\title{
Rikkakasvit herneen viljelyn haasteena
}

\author{
Jukka Salonen, Terho Hyvönen ja Heikki Jalli \\ MTT Kasvinsuojelu, 31600 Jokioinen, jukka.salonen@mtt.fi
}

\section{Tiivistelmä}

Rehuvalkuaisen omavaraisuutta voidaan turvata lisäämällä herneen viljelyä. Herneen viljelyvarmuutta ja viljelyn kannattavuutta pitäisi kuitenkin parantaa, jotta viljelijät kiinnostuisivat herneen viljelystä ja rehuteollisuus saisi näin riittävästi raaka-ainetta. Herneen kasvinsuojeluun liittyvät haasteet ovat omalta osaltaan rajoittaneet herneen viljelyn yleistymistä.

MTT:n tutkimushankkeeseen "Kotimaista valkuaista herneestä" sisältyi vuosina 2002-2003 hernepeltojen rikkakasvikartoitus. Varsinais-Suomesta, Hämeestä, Satakunnasta ja Uudellamaalta valittiin satunnaisesti tutkimustiloja, jotka MMM/TIKE:n tilastotietojen mukaan olivat viljelleet hernettä vuosina 1997-2001. Kartoituksen kohteena olivat pellot, joilla viljeltiin kuivaherneeksi tarkoitettuja ruokaherne-, rehuherne- ja seoskasvustoja. Tarkoituksena oli selvittää, mitkä rikkakasvilajit ovat yleisimpiä ja runsaimpia herneviljelyksillä, mitkä tekijät vaikuttavat rikkakasvien esiintymiseen ja millä keinoin ja tuloksin rikkakasveja torjutaan.

Tutkittuja peltolohkoja oli yhteensä 183, joista 119 oli tavanomaisesti ja 64 luonnonmukaisesti viljeltyjä. Rikkakasvien esiintyminen havainnoitiin viideltä $1 \mathrm{~m}^{2}$ näyte-alalta käyttäen luokittelevaa peittävyysasteikkoa (0-3). Lajiston koostumuksen vaihtelua ja sitä selittäviä tekijöitä tutkittiin ordinaatiomenetelmin (redundanssianalyysi RDA).

Hernepelloilta tavattiin yhteensä 76 rikkakasvilajia. Tavanomaisesti viljellyillä pelloilla kasvoi keskimäärin 10 lajia ja luomupelloilla 18 lajia. Yleisimmät lajit olivat jauhosavikka, pillikkeet, pihatähtimö, pelto-orvokki ja kestorikkakasveista juolavehnä. Leveälehtisistä kestorikkakasveista peltovalvatti oli yleisempi kuin pelto-ohdake. Hernettä viljeltiin yleensä viljavaltaisissa kierroissa. Niinpä rikkakasvilajisto vastasi kevätviljapeltojen vastaavissa kartoituksissa havaittua lajistoa.

Suurin vaihtelu lajiston koostumuksessa oli luonnonmukaisesti ja tavanomaisesti viljeltyjen lohkojen välillä. Torjunta-aineiden käyttö ja nurmen esiintyminen viljelykierrossa selittivät vaihtelua. Rikkakasvit torjuttiin kemiallisesti 92 \%:lla tavanomaisesti viljellyistä pelloista. Kolme suosituinta valmistetta olivat Senkor (metributsiini), Basagran SG (bentatsoni) ja Basagran MCPA (bentatsoni + MCPA). Valmisteiden teho oli yleensä hyvä, mutta herneen rikkakasvien kemiallinen torjunta on kallista 26-90 €/ha. Ruiskutettujen peltojen ongelmalajeiksi erottuivat metributsiinia kestävä peltomatara ja bentatsonia kestävä pelto-orvokki. Mekaanisesti rikkakasveja torjuttiin viidellä luomupellolla.

Hernepeltojen rikkakasveja voidaan torjua varsin tehokkaasti lajiston mukaan valituilla torjuntaaineilla, mutta luomuviljelyssä rikkakasvit ovat ongelma. Rikkakasvien mekaaninen torjunta haraamalla ja herne/kaura-seoskasvustot parantaisivat luomuherneen viljelyvarmuutta. Rikkakasvit sinänsä eivät aseta merkittäviä esteitä herneen viljelyn mahdolliselle laajentumiselle.

\section{Asiasanat}

kasvinsuojelu, rikkakasvit, rikkakasvien torjunta, biodiversiteetti, peltoherne, Pisum sativum L. 


\section{Johdanto}

Peltohernettä (Pisum sativum L.) viljellään Suomessa vain alle 5000 ha alalla, mikä vastaa noin 0,25\% viljellystä peltopinta-alasta (Maa- ja metsätalousministeriö 2004). Noin kolmasosa kuivaherneen viljelyalasta oli tarkastetun luomutuotannon piirissä vuosina 2002-2003. Hernettä viljellään tavallisesti viljavaltaisissa kierroissa joko puhdaskasvustona tai seoskasvustona viljan, yleensä kauran, kanssa. Herne olisi erinomainen vaihtoehto tiloille, joilla viljellään viljaa lähes monokulttuurina. Herneen heikko viljelyvarmuus, kalliit viljelykustannukset ja heikko kannattavuus kuitenkin rajoittavat viljelijöiden kiinnostusta herneen viljelyyn. Herneen kasvinsuojelukin on varsin haasteellista.

MTT:n johtaman tutkimushankkeen "Kotimaista valkuaista herneestä" (KOVAHERNEprojekti, 2002-2004) tavoitteena oli kehittää taloudellisia ja kilpailykykyisiä herneen tuotantomenetelmiä sekä tuottaa uutta tietoa kotimaassa viljellyn herneen viljelyvarmuudesta ja laadusta. Rehuherneen viljelystä ja sen mahdollisesta laajentumisesta aiheutuvien kasvinsuojeluongelmien ennakointi ja hallinta sisältyivät tutkimushankkeen tavoitteisiin.

Kotimaisia tutkimuksia peltoherneen kasvintuhoojista on varsin vähän, ja nekin pääasiassa 1960-ja 1970 -luvulta (mm. Ekholm 1961, Ruokola \& Kössi 1977). Rikkakasvien osalta tutkimuksen kohteena ovat lähinnä olleet uudet torjunta-aineet (Ruuttunen 1999). KOVAHERNE-projektin kasvinsuojeluosion tavoitteena olikin määrittää herneen viljelyä eniten rajoittavat kasvintuhoojat, niiden käytännön merkitys ja torjuntamahdollisuudet. Herneen viljelyn mahdollisen yleistymisen myötä kasvinsuojeluun, erityisesti kasvitauteihin (Lindroos \& Avikainen 2004) ja tuhoeläimiin (Huusela-Veistola \& Jauhiainen 2006) liittyvien uhkien oletetaan lisääntyvän.

Hernepeltojen rikkakasvillisuus ja rikkakasvien torjuntamenetelmät kartoitettiin osana kasvintuhoojien esiintymisrunsauden tutkimusta vuosina 2002-2003. Tavoitteena oli selvittää, mitkä rikkakasvilajit ovat yleisimpiä ja haitallisimpia, mitkä tekijät vaikuttavat rikkakasvien esiintymiseen ja miten rikkakasveja käytännössä torjutaan tavanomaisesti ja luonnonmukaisesti viljellyillä pelloilla.

\section{Aineisto ja menetelmät}

Hernepeltojen rikkakasvit kartoitettiin herneen viljelyn tärkeimmällä alueella Lounais- ja EteläSuomessa (kuva 1). Tutkimukseen osallistuneet tilat valittiin satunnaisotannalla käyttäen apuna MMM:n tietopalvelukeskuksen tilastotietoa hernettä vuosina 1997-2001 viljelleistä tiloista. Tutkimuksen kohteeksi sisällytettiin sekä alueita, joilla hernettä viljeltiin yleisesti että alueita, joilla herneen viljely oli ollut satunnaista. Useimmat tutkimuksessa mukana olleet luomuherneviljelmät olivat tiloilta, jotka olivat siirtyneet luonnonmukaiseen tuotantoon 1990-luvun puolivälissä.

Vuosina 2002-2003 kartoitettiin yhteensä 183 hernepellon rikkakasvilajisto. Näistä 119 peltoa olivat tavanomaisesti viljeltyjä ja 64 peltoa luomutuotannossa. Useimmissa tapauksissa tilalla viljeltiin hernettä 1-3 lohkolla. Yleisin esikasvi oli kevätvilja. Nurmea viljelykierrossa oli ollut 22 \%:lla tavanomaisesti viljellyistä hernepelloista ja 82 \%:lla luonnonmukaisesti viljellyistä hernepelloista.

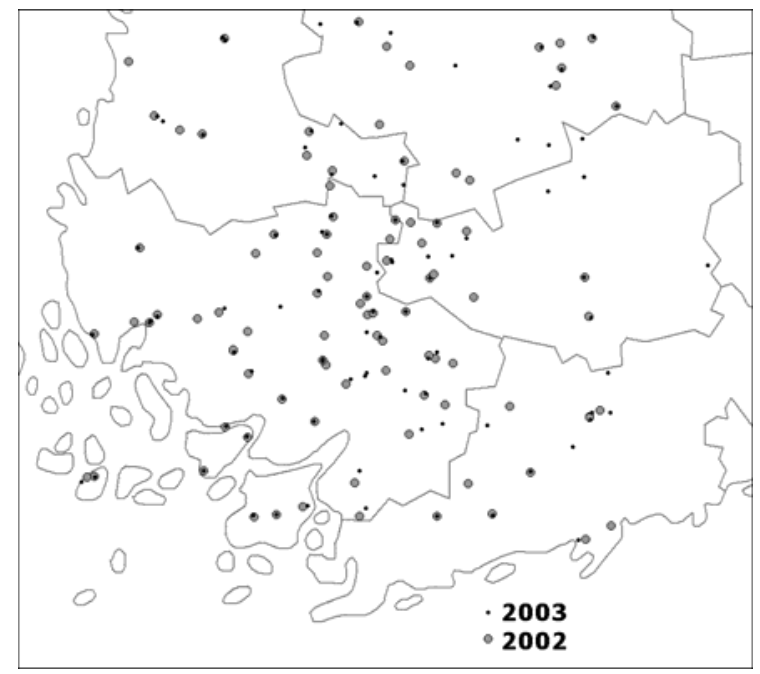

Kuva 1. Rikkakasvikartoituksessa mukana olleiden hernepeltojen sijainti Lounais- ja Etelä-Suomessa. 
Rikkakasvihavainnot ajoittuivat heinäkuun alkuun, jolloin tavanomaisesti viljellyillä pelloilla rikkakasvit oli ehditty torjua kemiallisesti kesäkuun aikana. Jokaiselta pellolta arvioitiin viideltä satunnaisesti sijoitetulta $1 \mathrm{~m}^{2}: \mathrm{n}(1 \mathrm{~m} \times 1 \mathrm{~m})$ näyteruudulta rikkakasvien peittävyys lajeittain asteikolla $0-3$ ( $0=$ =ei esiinny, $1=$ =eittävyys alle $5 \%$, 2=peittävyys 5-25\%, 3=peittävyys yli $25 \%$ ). Aineiston analyysivaiheessa viiden näyteruudun arvot yhdistettiin. Rikkakasvien yleisyys-\% kuvaa, kuinka monelta havaintopellolta kutakin lajilta tavattiin. Rikkakasvien runsaus puolestaan tarkoittaa peittävyysarvioon perustuvaa kasvien rehevyyttä.

Herneen viljelyä ja kasvinsuojelua koskevat tiedot saatiin haastattelemalla viljelijöiltä. Tietoja käytettiin selittävinä muuttujina analysoitaessa rikkakasvilajiston koostumuksen vaihtelua ja eri rikkakasvilajien esiintymiseen vaikuttavia tekijöitä ordinaatiomenetelmin CANOCO-ohjelmistolla. Selittävinä muuttujina käytettiin tuotantomuotoa (luomu/tavanomainen) sekä hernekasvustoon, viljelytekniikkaan (sis. rikkakasvien torjunta), kasvinvuorotukseen ja maaperään liittyviä tekijöitä. Analyysimenetelmänä käytettiin redundanssianalyysiä (RDA), jossa selittävien tekijöiden tilastollinen merkitsevyys testattiin Monte Carlo -permutaatiomenetelmällä.

\section{Tulokset ja tulosten tarkastelu}

Hernepeltojen yleisimpiä rikkakasveja olivat jauhosavikka, pihatähtimö ja pelto-orvokki (kuva 2). Kartoituksessa havaittiin yhteensä 76 rikkakasvilajia, joista 59 lajia tavattiin tavanomaisesti viljellyiltä pelloilta ja 68 lajia luonnonmukaisesti viljellyiltä pelloilta. Pelkästään luomupelloilla esiintyneitä lajeja olivat mm. siankärsämö, peltokanankaali, hevonhierakka ja otavalvatti. Vain tavanomaisesti viljellyillä pelloilla havaittuja lajeja olivat kylämaltsa, hukkakaura ja mustakoiso. Kaikki edellä mainitut lajit tosin olivat satunnaisia muutamilla lohkoilla tavattuja lajeja. Tavanomaisesti viljellyillä hernepelloilla kasvoi keskimäärin 10 rikkakasvilajia (min 3, max 21 lajia/pelto) ja luonnonmukaisesti viljellyillä pelloilla keskimäärin 18 lajia (min 8, max 31 lajia). Tämä tulos tukee muissakin rikkakasvikartoituksissa (mm. Hald 1999, Salonen ym. 2001) tehtyä johtopäätöstä, jonka mukaan luomuviljely suosii kasvilajiston monimuotoisuutta.

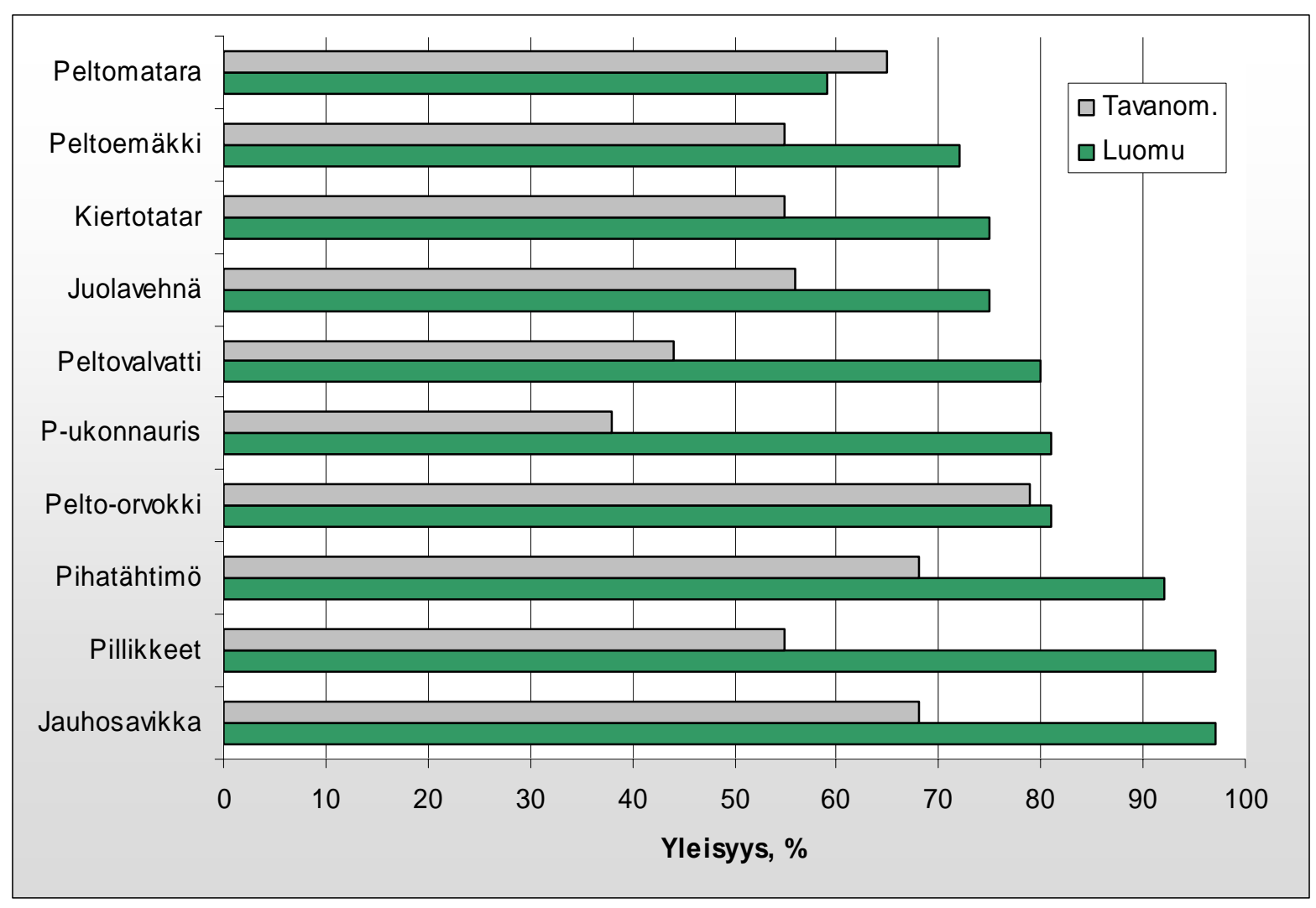

Kuva 2. Hernepeltojen yleisimmät rikkakasvit. 
Yleisimmät ja runsaimpina esiintyneet lajit olivat tyypillisiä kevätviljapeltojen rikkakasveja (vrt. Salonen ym. 2001). Peittävyysarvion perusteella runsaimpina esiintyneet lajit tavanomaisessa viljelyssä olivat pelto-orvokki, jauhosavikka, peltomatara, pihatähtimö ja pillikkeet. Luonnonmukaisesti viljellyillä pelloilla runsaimpina esiintyneet lajit olivat puolestaan jauhosavikka, pihatähtimö, pillikkeet, juolavehnä ja peltoukonnauris. Juolavehnä oli yleisin kestorikkakasvi, ja peltovalvattia kasvoi hernepelloilla yleisemmin kuin pelto-ohdaketta.

Rikkakasvihavaintojen ja viljelytietojen pohjalta tehty RDA-analyysi osoitti, että tavanomaisesti ja luonnonmukaisesti viljellyt hernepellot poikkesivat rikkakasvilajistoltaan toisistaan. Luomupelloille tyypillisiä lajeja olivat mm. peltohatikka, peltoukonnauris ja rönsyleinikki. Ordinaatioanalyysin toinen akseli (y-akseli) puolestaan korreloi mm. kasvuston peittävyyteen, maalajiin ja muokkaukseen (kuva 3). Herbisidien käytön vaikutus rikkakasvillisuuteen todettiin niin tässä aineistossa kuin aiemmissa kartoituksissa (mm. Hald 1999, Hyvönen \& Salonen 2002). Ruiskutetuilla hernepelloilla tyyppilajeina olivat viljelijöiden valitsemia herbisidejä kestäneet peltomatara ja peltoemäkki.

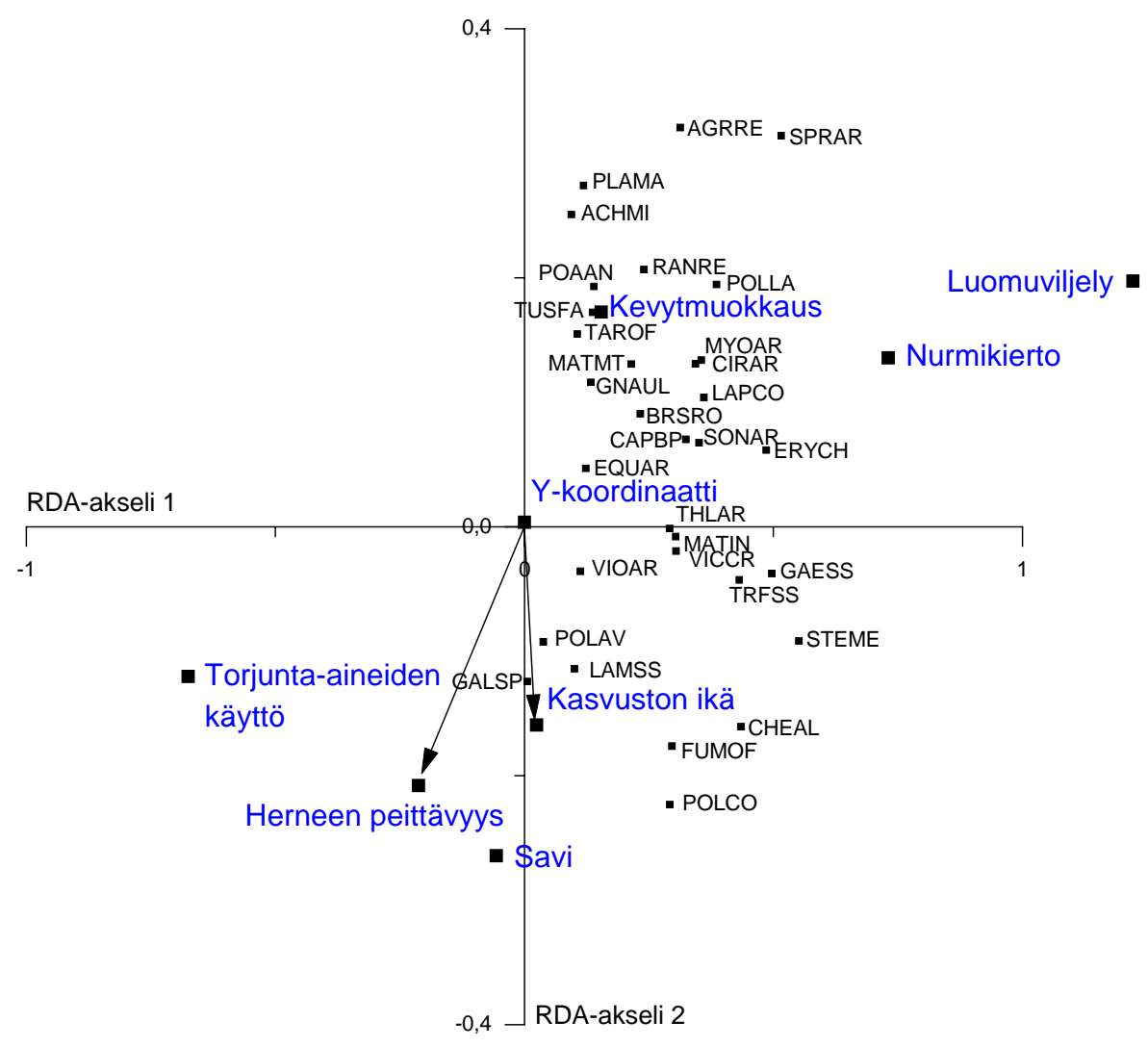

Kuva 3. Redundanssianalyysillä (RDA) osoitetut tärkeimmät hernepeltojen rikkakasvillisuuteen vaikuttavat tekijät. Rikkakasvilajit kuvattu latinankielisistä nimistä johdetuin Bayer-koodein (kts. Salonen ym. 2005)

Tavanomaisessa viljelyssä rikkakasvien kemiallinen torjunta oli yleistä; 92 \% tutkituista lohkoista oli ruiskutettu leveälehtisten rikkayrttien torjuntaan hyväksytyillä valmisteilla. Eri valmisteiden tankkiseokset olivat yleisiä, mikä laajentaa kunkin valmisteen tehoa eri rikkakasveihin. Juolavehnää oli torjuttu heinämäisten rikkakasvien valikoivilla torjunta-aineilla (Agil, Fusilade, Targa Super) vain seitsemällä tutkimuslohkolla. Rikkakasvien mekaaninen torjunta kasvukauden aikana oli vieläkin harvinaisempaa; vain viidellä lohkolla rikkakasvit oli harattu. Tässä tutkimuksessa ei kerätty tietoa rikkakasvien torjunnan vaikutuksesta herneen satoon, mutta kenttäkokeissa herneestä on saatu jopa 500 $\mathrm{kg} / \mathrm{ha}$ parempi sato kuin ruiskuttamattomilta ruuduilta (Ruuttunen 1999). Torjunnalla saadun sadonlisäyksen tulisi kattaa aiheutuneet kustannukset, jotka pelkästään valmisteiden osalta ovat 26-90 €/ha. 


\section{Johtopäätökset}

Hernettä viljeltiin yleisimmin viljavaltaisissa kierroissa, mikä heijastui myös viljapelloille tyypillisenä rikkakasvilajistona hernevuonna. Monipuolisemman viljelykierron vaikutus rikkakasvilajistoon näkyi erityisesti niillä luomuhernelohkoilla, joiden viljelykiertoon sisältyi nurmea. Tutkimusalueelle sijoittuu yli puolet peltoherneen viljelyalasta Suomessa. Havaittu rikkakasvillisuus ei sinänsä ole esteenä herneen viljelyn toivotulle laajentumiselle, kunhan rikkakasvien torjunnasta huolehditaan.

Tavanomaisessa herneen viljelyssä rikkakasvien kemiallinen torjunta näyttää olevan jokavuotista rutiinia. Markkinoilla olevilla herbisideillä ja niitä tarvittaessa yhdistelemällä saadaan runsaimpina esiintyvät rikkakasvit torjuttua varsin tehokkaasti. Torjunnasta aiheutuva kustannus vain on moninkertainen verrattuna esim. kevätviljan rikkakasvintorjuntaan. Rikkakasvien jokavuotinen torjunta viljelykierrossa on suotavaa, sillä näin estetään rikkakasvien siemenpankin karttuminen. Peltoherneen rikkakasvintorjuntaan hyväksytyt valmisteet ovat vaikutusmekanismiltaan erilaisia kuin viljoille hyväksytyt valmisteet, mikä vähentää rikkakasvillisuuden valikoitumista torjunta-aineita kestävien lajien suuntaan. Tässä tutkimuksessa ei kerätty havaintoja torjunnan vaikutuksesta satoon, joten rikkakasvien torjunnan kannattavuutta tutkimukseen osallistuneilla tiloilla ei voitu arvioida.

Luonnonmukaisessa herneen viljelyssä rikkakasvit ovat selkeä sadonmuodostusta rajoittava tekijä. Rikkakasvien mekaaninen torjunta olisi mahdollista joskin Suomen oloissa heikosti tutkittua. Kuitenkin vain parilla tilalla rikkakasvit torjuttiin haraamalla. Toinen keino parantaa herneen mahdollisuuksia rikkakasveja vastaan on seosviljely esim. kauran kanssa, mikä lisäisi kasvuston kilpailukykyä etenkin kasvukauden alkuvaiheessa.

\section{Kiitokset}

Kiitämme kaikkia kasvintuhoojakartoitukseen osallistuneiden maatilojen viljelijöitä, jotka antoivat meille tietoja herneen viljelystä omalla tilallaan ja sallivat näytteiden keruun hernelohkoiltaan. Prof. Pirjo Peltonen-Sainion johtaman "Kotimaista valkuaista herneestä” -projektin kasvinsuojeluosio oli MMM:n (MAKERA) ja MTT:n rahoittama.

\section{Kirjallisuus}

Ekholm, S. 1961. Hernekääriäinen ja sen torjunta. Maatalous ja koetoiminta XV, 228-234.

Hald, A.B. 1999. Weed vegetation (wild flora) of long established organic versus conventional cereal fields in Denmark. Ann. Appl. Biol. 14: 307-314.

Huusela-Veistola, E. \& Jauhiainen, L. 2006. Herneen viljelyn laajeneminen lisää hernekääriäisriskiä. In: Maataloustieteen Päivät 2006, Viikki 11.-12. 1. 2006 (posteri).

Hyvönen, T. \& Salonen, J. 2002. Weed species diversity and community composition in cropping practices at two intensity levels - a six-year experiment. Plant Ecol. 159: 73-81.

Larsen, H.L.F. \& Andreasen, C. 2004. The sensitivity of field peas (Pisum sativum L.) to weed harrowing. In: Proceedings of the $6^{\text {th }}$ EWRS Workshop on Physical and Cultural Weed Control, Lillehammer, Norway. p. 5557. (Available on the Internet: http//www.ewrs.org/pwc/pdf/2004_Lillehammer_corrected.pdf. Updated 22 December 2004.

Lindroos, M. \& Avikainen, H. 2004. Viljelykierrolla herneen taudit kuriin. Koetoim. Käyt. 61(nro 4): 14. Maa- ja metsätalousministeriö 2004. Maatilatilastollinen vuosikirja 2004. Maa- ja metsätalousministeriön tietopalvelukeskus. Maa- metsä- ja kalatalous 2004: 61. 268 s.

Ruokola, A-L. \& Kössi, L. 1977. Fungus diseases of pea seeds and stands in Finland. Acta Agriculturea Scandinavica 27: 89-104

Ruuttunen, P. 1999. Evaluation of herbicides in pea. In: Ruoho, T. (ed.). Trial report - Herbicides and plant growth regulators. MTT Agrifood Research Finland, p. 236-251.

Salonen, J., Hyvönen, T. \& Jalli, H. 2001. Weeds in spring cereal fields in Finland - a third survey. Agric. and Food Sci. in Finland 10: 347-364.

Salonen, J., Hyvönen, T. \& Jalli, H. 2005. Weed flora and weed management of field peas in Finland. Agric. and Food Sci. 14: 189-201. 